\title{
Cost/Benefit Evaluation Of Sulaibiya Wastewater Treatment Plant In Kuwait
}

\author{
Jasem M. Alhumoud, Kuwait University, Kuwait \\ Hanouf Al-Humaidi, Kuwait University, Kuwait \\ Ibrahim N. Al-Ghusain, Utilities Development Company, Kuwait \\ Ali M. Alhumoud, Kuwait Institute for Scientific Research, Kuwait
}

\begin{abstract}
In May 2001, the Government of Kuwait awarded a build, operate and transfer (BOT) contract to a local company to finance, design, build and operate an advanced wastewater treatment plant (WWTP) at Sulaibiya. The contract has a 30-year life, comprising 30 months of design and build and 27.5 years of operation and management. The total project cost was K.D. 116 million (US\$ 442 million). The Sulaibiya plant currently treats up to 375 million imperial gallons. It is designed for extension to 600 million imperial gallons and is the first of its kind to be built in the Middle East. It is the largest in the world to use ultrafiltration (UF) and reverse osmosis (RO) for water purification. Ultrafiltration will remove all suspended solids and will provide a substantial reduction in micro biological activities. The main obstacle against the use of ultrafiltration membranes for WWTP has always been the higher operating cost of ultrafiltration. Up until now, this higher cost has prevented implementation of UF in all plants. A new membrane has been designed with the aim of tailoring it toward lowest total cost of ownership. Typical operating conditions have been used to quantify the following parameters for a potential large scale wastewater treatment system $(U F+R O)$ : amortization of investment in UF membranes and equipment; operating costs of the UF system; reduction in operating costs of the RO, when being compared against a conventional treatment system; and the increased output of the RO plant due to higher availability and shorter construction time. The total cost of ownership of a UF based RO plant has been determined (expressed in US\$/m3 of water produced). Taking all factors into account, the total cost of ownership of a dual membrane WWTP $(U F+R O)$ will be 2-7\% lower than the total cost of ownership of on conventional retreatment plant.
\end{abstract}

Keywords: benefit, cost, Kuwait, ultrafiltration, reverse osmosis, Sulaibiya

\section{INTRODUCTION}

C n May 2001, the Government of Kuwait awarded a build, operate and transfer (BOT) contract to Mohammed Abdulmohsin Al-Kharafi \& Sons Company (The Kharafi Group) to finance, design, build and operate an advanced wastewater treatment plant (WWTP) at Sulaibiya (Figure 1). AL-Kharafi, a Kuwaiti family-owned group, has a $\$ 3.3$ billion turnover and has constructed over 1,250 projects. The group is the largest contractor in Kuwait with 30 sewage treatment construction contracts under its belt. The contract has a 30 year life, comprising 30 months of design and build and 27.5 years of operation and management. Construction started in July 2002 and was completed in November 2004. The total project cost was K.D. 116 million (US\$ 442 million) and projected revenues to UDC over the duration of the concession are in excess of $\$ 2$ billion. The winning tariff bid by the consortium was KD. $0.142 / \mathrm{m}^{3}\left(\$ 0.47 / \mathrm{m}^{3}\right)$. Shortly after its completion, it won 'Wastewater Project of the Year' in the 2005 Global Water Awards. The judges described it as a "powerful statement of the future of water resources across the whole Middle East and North Africa region" (Gottberg et al, 2003; Gottberg and Vaccaro, 2003). 


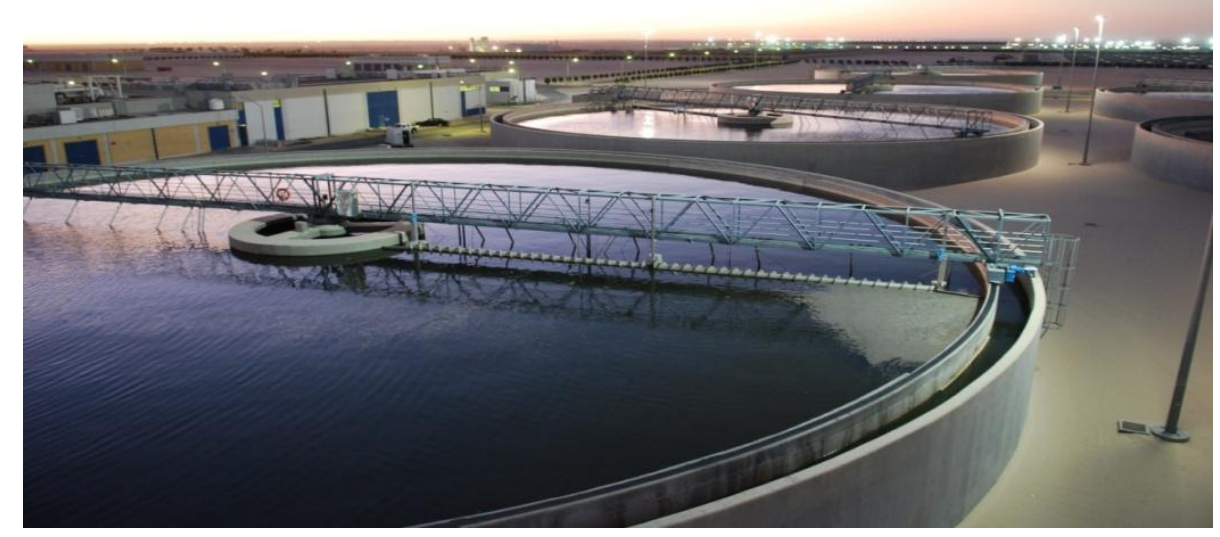

Figure 1: Wastewater Treatment Facility at Sulaibiya near Kuwait City

The Sulaibiya plant currently treats up to 375 million imperial gallons. It is designed for extension to 600 million imperial gallons and is the first of its kind to be built in the Middle East. It is the largest in the world to use ultrafiltration (UF) and reverse osmosis (RO) for water purification. The major treatment steps for the project are shown in Figure 2 (Gottberg et al, 2003; Gottberg and Vaccaro, 2003).

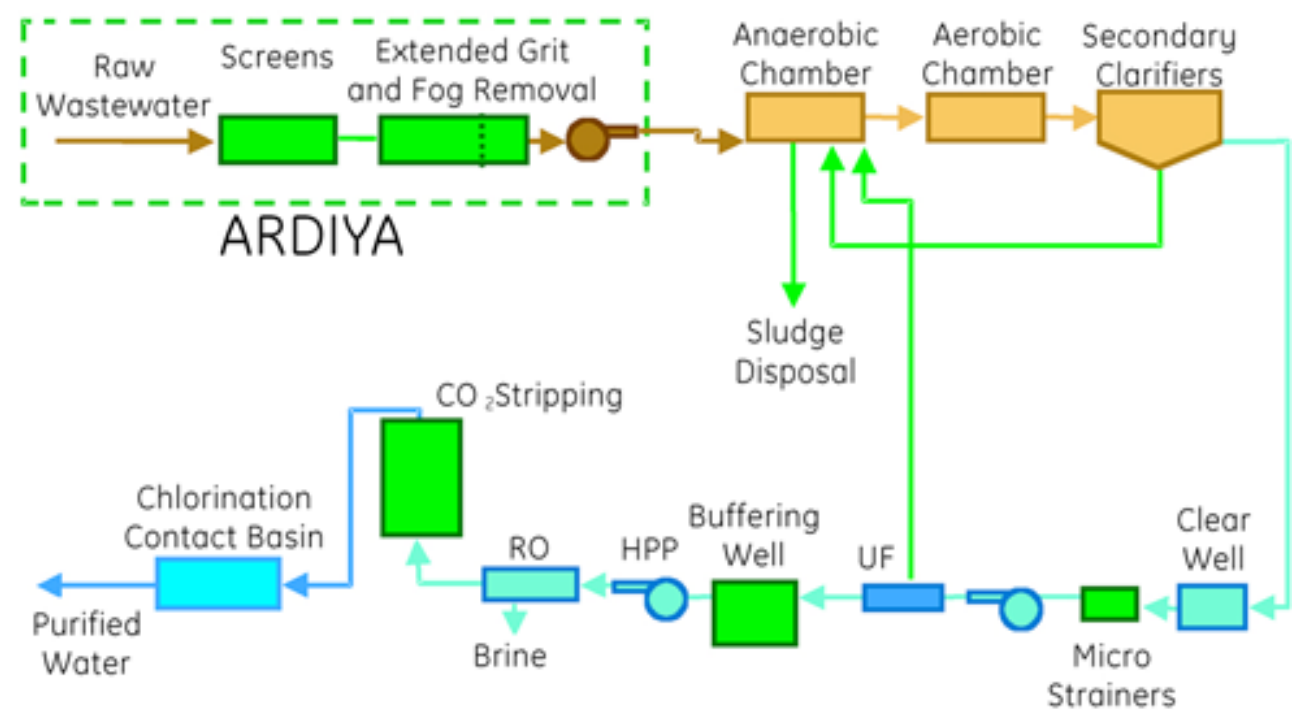

Figure 2: Major Treatment Steps at Suaibiya Plant

The basic idea of the Sulaibiya Wastewater Treatment and Reclamation Project (WWT\&RP) is to replace the existing Ardiya WWTP by a new plant. The existing plant in Ardiya is no longer able to treat the increasing amount of waste water. The tertiary treated effluent from Ardiya plant contained a very high load of flocculated suspended solids, which required a much greater filter capacity than that used for sea water or ground water. The brackish water resources are no longer sufficient to cover the increasing non-potable water demand. Therefore, municipal effluent is given preliminary treatment at Ardiya and then piped $25 \mathrm{~km}$ (16 miles) to the Sulaibiya facility. 
The water quality used as the basis of design and the projected treated water quality are detailed in Table 1 . The plant influent is typical domestic sewage. The WWTP is designed to produce an effluent with an average monthly value of less than $20 \mathrm{mg} / \mathrm{l} \mathrm{BOD}$ and $20 \mathrm{mg} / \mathrm{l} \mathrm{TSS}$. The water reclamation plant is designed to accommodate peaks in water quality due to upsets in performance of the WWTP. The average total dissolved solids (TDS) in the feed is $1,280 \mathrm{mg} / \mathrm{l}$, and the plant product is less than $100 \mathrm{mg} / \mathrm{l}$, significantly better than World Health Organization (WHO) potable water guidelines.

Table 1: Water Quality Data

\begin{tabular}{|c|c|c|c|}
\hline Parameters & Effluent Plant* & Membrane Plant* & WHO Guidelines*** \\
\hline $\mathrm{PH}$ & 7 & $6-9$ & $6.5-8.5$ \\
\hline $\mathrm{TSS}(\mathrm{mg} / \mathrm{l}) * * *$ & 12 & $<1$ & \\
\hline BOD (mg/l) & 5 & $<1$ & \\
\hline Ammonia Nitrogen as N (mg/l) & $<2$ & $<1$ & \\
\hline Nitrate (mg/l as $\mathrm{N})$ & $<9$ & $<1$ & 10 \\
\hline Phosphate (mg/l as PO4) & $<15$ & 2 & \\
\hline Fat, oil and grease $(\mathrm{mg} / \mathrm{l})$ & $<0.5$ & $<0.5$ & \\
\hline TDS (mg/l) & $<1280$ & 100 & 1000 \\
\hline
\end{tabular}

* Average monthly value; $* *$ for potable water; $* * * \pm 50 \%$

UF has been generally accepted as the proper pretreatment to spiral wound membranes for effluent polishing applications. The alternative would require an extensive train of several treatment steps with associated high investment and operating costs, while RO feed water quality cannot be guaranteed $100 \%$ of the time. UF guarantees a constant water quality at low cost, virtually independent of the feed water quality. Figure 3 shows the UF system installed at Sulaibiya, Kuwait. In addition it has also been accepted as an alternative to conventional pretreatment for brackish surface water RO systems. For example, in the Netherlands, a UF plant has been successfully operated since 1999 (Figure 4) (Bruin et al., 2002).

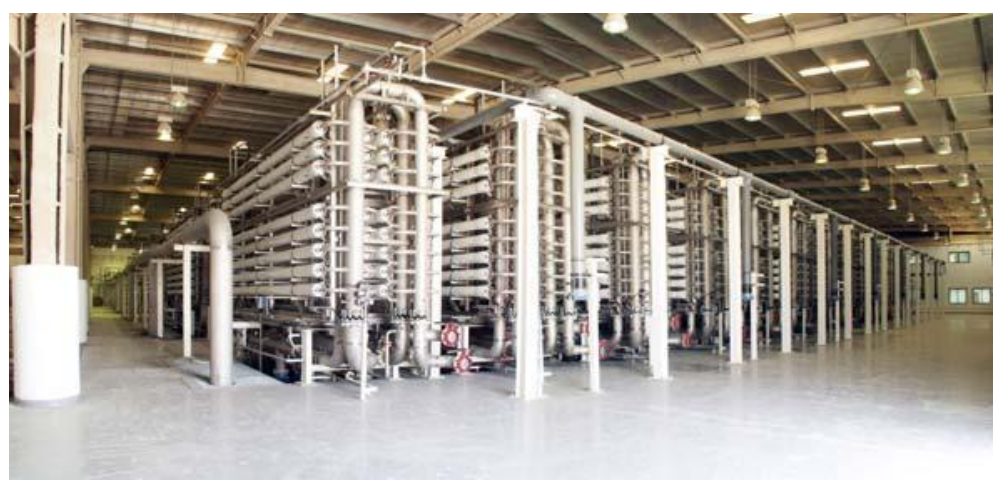

Figure 3: UF Plant at Sulaibiya, Kuwait

UF pretreatment to sea water has been piloted in many places around the world. All these plants achieved the target filtrate qualities required by the suppliers of spiral wound RO elements. Typical levels are set at: turbidity 0.1 NTU and SDI level 3. Despite the technical success, still very few dual membrane desalination plants are in operation. Moreover, plants in UAE, Saudi Arabia, Bahrain and China are in operation or under construction (Basha, et al., 2005; Galloway, et al., 2003; Burashid, et al., 2005). Generally, authorities consider it technically feasible to use UF to wastewater treatment, but economically unviable (Gleuckstern and Priel, 2003; Cole et al., 2005). This paper shows an economic evaluation of the Sulaibiya wastewater treatment plant that uses UF pretreatment. 


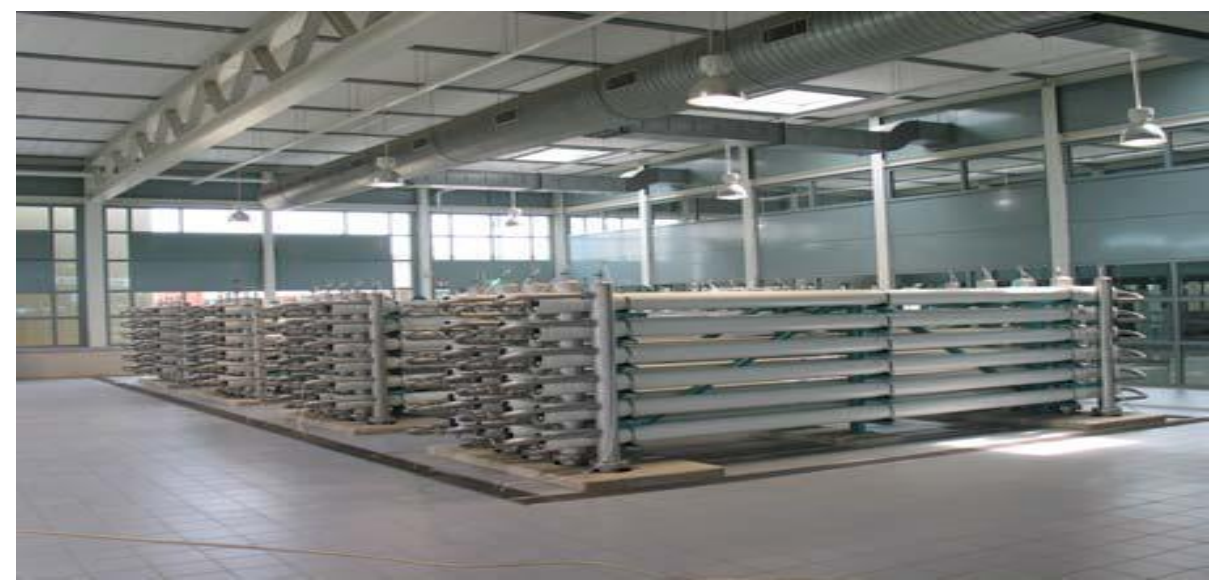

Figure 4: UF Plant at Heemskerk, the Netherlands

\section{ULTRAFILTRATION SYSTEM}

Membrane filtration was selected to provide robust pretreatment of the secondary-treated municipal effluent before being fed to the RO. Membrane filtration was chosen over conventional tertiary clarification and filtration because it reduced the plant chemical consumption and could guarantee that low turbidity water is fed to the RO. It is expected that better quality pretreatment to the RO will lead to longer membrane life, lower operating pressure, and reduced cleaning frequency for the RO system. Without the use of pre-RO membrane treatment, using today's more highly efficient RO membranes, is impossible. Thin film composite (TFC) membranes would suffer quick fouling. Also, the combination of UF and RO removes bacteria and pathogens and provides potable quality water suitable for agriculture or groundwater recharge (Iwahori, 2005; Futselarr, et al., 2004). Bids for the membrane filtration system were solicited from major suppliers of membrane filtration equipment. After a thorough evaluation, Norit's UF technology was selected. The technology was selected both for favorable life cycle costs and, since this is a UF membrane, for the better quality of water to the RO membranes. The ultrafiltration plant utilizes Norit's X-Flow membranes, which are capillary hydrophilic hollow fibers. These membranes are packaged in 8 " x 60" (20 cm x $152 \mathrm{~cm})$ membrane elements that provide $35 \mathrm{~m}^{2}\left(42\right.$ yards $\left.^{2}\right)$ of membrane area per element. Four membrane elements are placed inside a membrane housing, and 32 membrane housings are installed in each UF unit. This plant consists of 68 skids, each with 32 membrane housings for a total of 8,704 membrane elements. The plant is operated continuously and is fully automatic, with very little operator attention required. The UF units are operated individually. Each unit is backwashed regularly, whereby all suspended matter that is being retained by the membranes is removed from the plant. The backwash water is pumped back upstream of the WWTP to achieve the highest possible overall water recovery for the plant.

Occasionally, a low dose of chemicals is added during a backwash. This Chemically Enhanced Backwash (CEB) removes any matter that may have adhered to the membrane surface and is not removed by a hydraulic backwash alone. Since the backwash and CEB actions are scheduled on an individual unit basis, taking only a minor section of the plant out of filtration mode, the continuous flow of effluent from the biological plant can be accommodated. The effluent fed to the UF first passes through a disk filter, after which a small amount of coagulant is added to coagulate fine particulates and possibly allow some TOC removal to facilitate the operation of the plant.

The SDI of the UF product will be below 2, an important criterion for the RO plant performance. Previous experience treating secondary municipal effluent with UF has shown that SDI values of less than 1 are possible.

Therefore, we could say that the main characteristics for this new membrane are:

- $\quad$ Ultrafiltration for good removal of suspended solids, resulting in low turbidity and SDI.

- Hydrophilic polyethersulphon, for high permeability and low fouling tendency.

- $\quad$ Operated in dead-end flow in order to minimize the energy consumption.

- $\quad$ Pressurized inside-out filtration, allowing for direct feed from the intake works into the RO high pressure pumps. Interstage tanks and pumps can be eliminated. 
- Use of short cleaning cycles, so called chemically enhanced backwashes. This mode of operation minimizes the flow fluctuations to the RO system.

\section{REVERSE OSMOSIS SYSTEM}

The salinity of the municipal effluent has an average monthly value of $1,280 \mathrm{mg} / \mathrm{l} \mathrm{TDS}$, with a maximum value of $3,014 \mathrm{mg} / \mathrm{l}$. RO is used to desalinate the water to $100 \mathrm{mg} / \mathrm{l} \mathrm{TDS}$, as well as provide a second barrier to bacteria and viruses. RO technology is well proven for desalinating municipal effluent. The system consists of 42 identical skids in a 4:2:1 array. Approximately 21,000 membranes, provided by Toray of America, were required for this project. The RO system is limited to operating at $85 \%$ recovery by calcium phosphate precipitation, which can frequently be the limiting factor for water recovery in membrane systems desalinating municipal effluent. The RO product passes through a stripper to remove carbon dioxide to adjust $\mathrm{pH}$ with a minimum amount of caustic before distribution and the product is then chlorinated before leaving the plant. RO brine is disposed of into the Gulf.

\section{TOTAL COST OF OWNERSHIP}

The total cost of ownership (TCO) is the cost being calculated over the life cycle of a treatment plant. This can be either the contract period of a BOT project (in this case 30 years) or the technical life of the mechanical and civil constructions. This cost has been compared for a number of desalination plants realized under construction of being planned. The government of Kuwait heavily subsidizes water production. While 1,000 imperial gallons (IG) $\left(4,545 \mathrm{~m}^{3}\right)$ of water costs the Ministry of Electricity and Water (MEW) KD 3.855 (US\$ 14.26) to produce, the customer is charged KD 0.8 (US\$ 2.96) for it. On the other hand, AL-Kharafi Company sells 1,000 IG of the treated wastewater produced from Sulaybia plant to MPW for KD 0.800 (US\$ 2.81) and MPW charges customers (farmers) only KD 0.200 (US\$ 0.74 ) for it. Tertiary treated wastewater costs MPW KD 0.400 (US\$1.48); however, since the Sulaybia plant treats wastewater with the additional processes of UF and RO, it therefore costs an additional KD 0.500 (US\$ 1.85). In view of the rapidly increasing cost of water supply schemes, inflation etc., the above rates still seem to be unreasonably low.

In general, the following general split can be made for the TCO (Menge et al., 2001; Henthorne, et al., 2005; Caneja, et al., 2005):

$\pm 17 \%$ Pretreatment

$\pm 6 \%$ RO membrane replacement and RO membrane cleaning

$\pm 27 \%$ Other fixed costs (amortization of other equipment etc.).

$\pm 50 \%$ Other variable costs (energy costs etc.)

When UF is selected as pretreatment for RO instead of conventional technology, the split in the total cost of ownership will change. If the sum of the individual parts of the TCO for UF is lower than the TCO as estimated above KD 0.023-0.024 per $\mathrm{m}^{3}$ (85-90 US cents $/ \mathrm{m}^{3}$ ), this implies that UF is not only technically feasible, but also economically attractive. It has to be noted that not only the actual cost of the pretreatment system has to be taken into consideration, but also the impact of the pretreatment system on the other costs (both fixed as well as variable). All costs have been assessed below and the impact of using UF as pretreatment has been quantified for the individual costs.

\subsection{Pretreatment} systems:

A large number of different conventional pre-treatment systems can be employed as pretreatment to SWRO

- $\quad$ Disinfection, flocculation and filtration do not always provide adequate filtrate quality (Al-Malek, 2005).

- The general recommendation for proper conventional pretreatment is the use of flocculation, dissolved air flotation and filtration, or the use of flocculation, settling and filtration (Clunie, et al., 2005). 
With conventional technology as pretreatment, the pretreatment part of TCO is approximately $17 \%$ of KD 0.023-0.024 per $\mathrm{m}^{3}\left(85-90\right.$ cents $\left./ \mathrm{m}^{3}\right)$, equals KD 0.0037-0.004 per $\mathrm{m} 3\left(14-15\right.$ US cents $\left./ \mathrm{m}^{3}\right)$. The pretreatment costs can be split in amortization of investment and operating costs (mainly chemicals for coagulation and for disinfection). When UF is being selected as pretreatment option over conventional technology, the investment costs for the pretreatment will increase. Thus, the fixed costs associated with pretreatment will increase. The costs for chemicals (mainly coagulant) will decrease, but a new cost arises - the cost of UF membrane replacement.

Approximately KD $0.00189-0.0021$ (7-8 US cents) of the total KD 0.0041 (15 cents) can be attributed to chemical dosing. With UF pretreatment, this can be reduced by at least 25-50\%. The other half of the KD 0.0041 (15 US cents) can be attributed to amortization of the pretreatment. With UF as pretreatment, there will be an increase by approximately $10-20 \%$. The new additional cost is for membrane replacement being approximately KD 0.0003 per $\mathrm{m}^{3}$ ( $1 \mathrm{US}$ cent $/ \mathrm{m}^{3}$ ) (taking into account a membrane life time of 8 years). With UF technology, the TCO part will be decreased by $0-20 \%$. An additional KD $0.0003 \mathrm{per} \mathrm{m}^{3}\left(1 \mathrm{US}\right.$ cent $\left./ \mathrm{m}^{3}\right)$ has to be added for UF membrane replacement. The portion "pretreatment" will be approximately KD $0.0032-0.0043$ per $\mathrm{m}^{3}\left(12-16 \mathrm{US}\right.$ cents $\left./ \mathrm{m}^{3}\right)$.

\subsection{RO Membrane Replacement and Cleaning}

With conventional technology as pretreatment, the RO replacement and RO cleaning part of TCO is approximately $6 \%$ of KD $0.023-0.024$ per $\mathrm{m}^{3}\left(85-90\right.$ cents $\left./ \mathrm{m}^{3}\right)$, which equals approximately KD 0.0014 per $\mathrm{m}^{3}(5$ US cents $/ \mathrm{m}^{3}$ ). When UF is being selected as the pretreatment option over conventional technology, the RO cleaning frequency will be greatly reduced. Pilots have shown that with UF as pretreatment, RO cleaning frequency can be virtually eliminated. Typical cleaning frequency can be reduced from once every $2-3$ months to once every 6-12 months. Because of the reduced RO fouling and the reduced chemical attack due to RO cleaning, the RO membrane life time will be increased when UF is being selected. It is safe to say that typical RO life can be increased from six years to at least seven years (conservative) with eight years or longer being realistic (Henthorne, et al., 2005).

Membrane replacement and membrane cleaning each make up 50\% of the cost [10]. The following estimate can be made for cost to be realized with UF pretreatment. RO cleaning will be reduced by $50 \%$ and RO replacement will be reduced by $15-30 \%$. The weighted average of both costs will be reduced by $30-40 \%$. With UF technology, the TCO part "RO membrane replacement and RO membrane cleaning" will be approximately KD 0.0008-0.0011 per $\mathrm{m}^{3}$ (3-4 US cents $\left./ \mathrm{m}^{3}\right)$.

\subsection{Other Fixed Costs}

With conventional technology as pretreatment, the 'fixed costs' part of TCO is approximately $27 \%$ of KD 0.023-0.024 per $\mathrm{m}^{3}\left(85-90\right.$ cents $\left./ \mathrm{m}^{3}\right)$ which equals KD 0.0062-0.0065 per $\mathrm{m}^{3}\left(23-24\right.$ US cents $\left./ \mathrm{m}^{3}\right)$. The fixed costs are a function of the on-line time of the desalination plant; the shorter the on-line time, the higher the fixed costs will be. This is because the fixed costs are being calculated in a fixed currency divided by the total net filtrate production over the complete life cycle. When the plant is not producing water, it reduces the net water production over its life time and thus increases the fixed costs expressed in costs per $\mathrm{m}^{3}$.

Compared to conventional technology, UF will provide the following benefits:

- Shorter construction time. This is an important factor in BOT contracts with a fixed life time. When the construction time can be decreased, the plant can produce water for a longer time. It is being assumed that the construction period can be reduced by 3-6 months. For a typical life time of 20 years, this means an increase in net production of $1-2 \%$.

- $\quad$ Because of the decreased RO cleaning frequency, the RO plant will have more operational days per year. If the $\mathrm{RO}$ cleaning duration is decreased by five days per year, the net RO output increases by approximately $2 \%$.

- $\quad$ Other fixed costs, such as land purchase, etc. will be reduced as well.

It is safe to assume an overall reduction of approximately $4 \%$ in the other fixed costs. With UF technology, the TCO part "other fixed costs" will be approximately KD 0.0059-0.0062 per $\mathrm{m}^{3}$ (22-23 US cents $\left./ \mathrm{m}^{3}\right)$. 


\subsection{Other Variable Costs}

With conventional technology as pretreatment, the 'variable costs' part of TCO is approximately $50 \%$ of KD 0.023-0.024 per $\mathrm{m}^{3}\left(85-90\right.$ cents $\left./ \mathrm{m}^{3}\right)$ which equals KD 0.011-0.0122 per $\mathrm{m}^{3}\left(42-45\right.$ US cents $\left./ \mathrm{m}^{3}\right)$. It can be argued that variable costs will be reduced when conventional pretreatment is replaced with UF membrane technology. Less RO fouling will lead to a lower flux decline and consequently in a lower RO operating pressure. A UF plant has a higher degree of automation, thus the labor requirement will be smaller. It is, however, difficult to quantify these cost savings. Therefore, these have not been taken into account. It is assumed that with UF pretreatment, the variable costs will also be KD 0.011-0.0122 per $^{3}$ (42-45 US cents $/ \mathrm{m}^{3}$ ).

\subsection{Total Cost of Ownership}

With conventional pretreatment, the total cost of ownership of the SWRO desalination plant is approximately KD $0.023-0.024$ per $\mathrm{m}^{3}$ (85-90 US cents $\left./ \mathrm{m}^{3}\right)$. With UF as pretreatment, the total cost of ownership of the dual membrane desalination plant will be KD 0.0214-0.024 per $\mathrm{m}^{3}$ (79-to 88 US cents $/ \mathrm{m}^{3}$ ). This provides a reduction in TCO of $2-7 \%$ when being compared with conventional pretreatment. In addition, the UF pretreatment provides the following non-quantifiable benefits:

- Less construction risk. The UF pretreatment needs substantially smaller civil works. Unstable soil conditions have less impact and the UF skids can be constructed in workshops and shipped to the site after the civil construction has been finished.

- $\quad$ Smaller footprint. Apart from cost savings in land purchase, this provides additional benefits, such as a greater freedom of choice for site location and potentially easier permitting for civil constructions.

- Water quality variations have a negligible influence on RO performance.

\section{ECONOMIC EVALUATION OF TREATED WASTEWATER}

In the monetary analysis of water reuse projects, it is important to distinguish between the cost and price of water. In an economic analysis, only the future flow of resources invested in or derived from a project is considered. Past resource investments are considered sunk costs that are irrelevant to future investment decisions. Thus, debt service on past investments is not included in an economic analysis. The price of water is the amount paid to a water wholesaler or retailer to purchase water. This is usually a combination of current and past expenditures for a combination of projects, as well as water system administration costs, which are generally fixed. For an economic analysis, only costs for future construction, operation and maintenance are relevant. As mentioned above, ALKharafi Company sells $4.545 \mathrm{~m}^{3}$ (1000 IG) of the treated wastewater produced by the Sulaybia plant to MPW for KD 0.800 (US\$ 2.96) and MPW charges customers (farmers) only KD 0.200 (US\$ 0.74 ) for it.

To estimate the cost of the tertiary treatment system at Sulaibiya, several sources from the published literature were used (Asano et al, 1996; Tchobanoglous and Angelakis 1996; MPW, 2001). Wastewater effluent reuse costs have two components: 1) the extra treatment needed to reach the reuse water quality requirement and 2) the extra transportation of the effluent to reuse sites. The financial benefits of reusing wastewater effluent are the value of fresh water saved and the cost of the alternative safe final disposal of the effluent when reuse is not practiced. The price of water in Kuwait is high compared to other countries. While $4.545 \mathrm{~m}^{3}$ (1000 IG) of water costs MEW KD 3.855 (US\$ 14.26) to produce, the customer is charged KD 0.80 (US\$ 2.96) for it. Water prices in the US are among the lowest in the developed world, with an average price of approximately US $\$ 0.6$ per $1 \mathrm{~m}^{3}$ (220 IG) compared to US\$2.2 in Germany. In Singapore domestic consumption of up to $40 \mathrm{~m}^{3}$ (8,799 IG) per month and non-domestic uses were charged at a uniform rate of US\$ 0.86 per $1 \mathrm{~m}^{3}$ (220 IG). For domestic consumption of more than 8,799 IG (40,000 liters) per month, the tariff became US\$ 1.03 per $1 \mathrm{~m}^{3}$ (220 IG) (Tortajada, 2006).

The unit costs for various stages of wastewater treatment and for fresh desalinated water are shown in Table 4.3. This is based on the assumption that each person would consume $0.505 \mathrm{~m}^{3}$ (111 IG) per day or 184.325 $\mathrm{m}^{3}$ (48,694 IG) per year. Costs include treatment (chemical addition, filtration, solids treatments), distribution, administrative (accounting, monitoring, overhead), and replacement reserve fees. 
Table 4.3: Cost of Water for Different Types of Treatment

\begin{tabular}{|c|c|c|c|}
\hline Type of effluent treatment & $\begin{array}{c}\text { Cost (US\$) } \\
\text { Per } 4.545 \text { m }^{3} \\
\end{array}$ & $\begin{array}{c}\text { Cost }(\text { US\$) } \\
\text { Per person per day }\end{array}$ & $\begin{array}{c}\text { Cost }(\text { US\$) } \\
\text { Per person per year }\end{array}$ \\
\hline Secondary- (1,000 Fecal Coliform/100 ml) & 2.13 & 0.24 & 88.00 \\
\hline Tertiary-(0 Fecal Coliform/100 ml) & 2.60 & 0.30 & 109.50 \\
\hline Advanced-(UF and RO) & 3.55 & 0.41 & 150.00 \\
\hline Desalinated water & 14.26 & 1.60 & 584.00 \\
\hline
\end{tabular}

Kuwait has a population of three million people; therefore, annual total cost to the country is US\$264 million for secondary treated wastewater, US\$ 328.5 million for tertiary treated effluent, and US\$ 450 million for advanced treated wastewater (UF and RO). These figures should be compared with US\$ 1.752 billion for desalinated water. Therefore, to use advanced treated effluent would cost the country US\$121.5 million a year more than using tertiary treated effluent. And using desalinated water would cost US\$1.4235 billion and US\$ 1.302 billion a year more than using tertiary and advanced treated effluents respectively. As the capital and operating costs of seawater desalination plants increase, the economic benefit of reuse will increase also. These numbers suggest that a wider range of uses of treated effluents should be given serious consideration.

\section{CONCLUSION AND RECOMMENDATIONS}

The water rates charged throughout the country are very low. While 1,000 IG of water costs MEW KD 3.90 (US\$ 14.26) to produce, the customer is charged KD 0.8 (US\$ 2.81) for it. In view of the rapidly increasing cost of water supply schemes, inflation etc., the above rates still seem to be unreasonably low. In contrast, ALKharafi Company sells 1,000 IG of the highly treated and purified treated wastewater produced by the Sulaybia plant to MPW for KD 0.800 (US\$ 2.81) and MPW charges customers (farmers) only KD 0.200 (US\$ 0.70) for it. Therefore, public awareness and education programs - perhaps the most important and necessary factor for an efficient water management system in the State of Kuwait - conducted by both the government and public/private interest groups can help promote treated wastewater reuse. Information flyers, booklets, and "home water guides" can provide the consuming households/industries with extensive lists of suggestions for reusing treated wastewater. The educational programs should strongly emphasize the negative health and environmental impacts of high water generation and poor water management.

Using UF membranes as pretreatment to RO wastewater treatment plants does not increase the cost associated with the pretreatment. The additional cost of having to replace the UF membranes at the end of their useful life time is more than offset by the cost reduction in use of chemicals (mainly coagulant).

If the total cost of ownership of a treatment plant is being calculated, there are a number of additional cost savings that can be achieved. The main cost savings can be achieved by a decrease in RO cleaning frequency (less use of chemicals, shorter down time and longer RO life time). Taking all factors into account, the total cost of ownership of a dual membrane wastewater treatment plant (UF + RO) will be $2-7 \%$ lower than the total cost of ownership of a RO plant based on conventional pretreatment.

The water authority should seriously think of reusing wastewater treated effluents. In many places around the world, secondary treated wastewater is used for irrigation. On the other hand, purified treated effluents are produced in Kuwait. Such high quality effluents can be used for many purposes without restriction. Alternatively, it could be discharged into artificially constructed wet lands, which may represent a viable option.

\section{ACKNOWLEDGMENTS}

The authors are thankful to the Ministry of Public Works and to Utilities Development Company for providing us with the information and data of the plant. In addition, the authors are grateful to the distinguished reviewers of the journal for their insightful comments and suggestions. 


\section{AUTHOR INFORMATION}

Dr. Jasem M. Alhumoud is an associate professor, professional engineer and consultant environmental/civil engineer. Currently working at Kuwait University in the Civil Engineering Department. He has a Ph.D. from the University of Pittsburgh, USA, in Civil and Environmental Engineering. His research and scholarly activities have been devoted to solid waste management, wastewater utilization/reuse and management, hydrology and hydraulics, geoenvironmental, geo-hydrology engineering, water resources engineering. In addition, he has done some work in coastal management. He has published more than 40 papers on those topics. Dr. J. Alhumoud can be contacted at the Civil Engineering Department, Kuwait University, P.O. Box 5969, Safat 13060, Kuwait, e-mail: Jasem@ @univ.edu.kw.

Hanouf Al-Humaidi is an assistant professor. Currently working at Kuwait University in the Civil Engineering Department. She has a Ph.D. from Ohio State University, USA. Her research interests are construction engineering and project management, fuzzy logic, scheduling, resources management. Safety in construction. Dr. Al-Humaidi can be contacted at the Civil Engineering Department, Kuwait University, P.O. Box 5969, Safat 13060, Kuwait, email: hanoufm@kuniv.edu.kw.

Ibrahim N. Al-Ghusain is an associate professor, professional engineer and consultant environmental/civil engineer. He has a Ph.D. in civil/environmental engineering from the University of Maryland, USA. Currently he is the general manager of Utilities Development Company. He is in charge of designing, planning and management of wastewater treatment plants. Dr. Al-Ghusain can contacted at the Utilities Development Company P.O. Box 24664, Safat, Kuwait, e-mail: ibrahim.alghusain@udch-kharafi.com

Ali M. Alhumoud is a researcher at the Kuwait Institute for Scientific Research in the Techno-Economics department. He has a Ph.D. in Industrial Engineering from the University of Cincinnati, USA. Conduct technoeconomic research and studies, and applying economic and mathematical models and quantitative methods. He is an Occupational and Environmental Health and Safety Expert. In addition, he has the following professional certificates: CIH - Certified Industrial Hygienist, USA - by the American Board of Industrial Hygiene, USA; CSP Certified Safety Professional - by the Board of Certified Safety Professionals, USA; CHCM - Certified Hazard Control Manager - by the Board of Certified Hazard Control Management, USA. Dr. Ali Al-Hemoud can be contacted at Kuwait Institute for Scientific Research P. O. Box 411 Code 72655 Alyarmook - Kuwait e-mail: ahomood@safat.kisr.edu.kw

\section{REFERENCES}

1. Al-Malek, A., Agashichev, S. and Abdulkarim, M., Techno-economic aspects of conventional pretreatment before reverse osmosis (Al Fujairah hybrid desalination plant), Proceedings IDA World Congress on Desalination and Water Reuse, Singapore, September 11-16, 2005.

2. $\quad$ Asano T, Maeda M and Takaki M., Wastewater Reclamation and Reuse in Japan: Overview and Implementation Examples, Water Science and Technology, Vol. 34, No. 11, pp. 219-226, 1996.

3. Basha, K., Saud, M., Gulamhusein, A., Nicoll, P. and Boda, P., Design and Construction Challenges of the Kindasa SWRO Desalination Plant Expansion, Proceedings IDA World Congress on Desalination and Water Reuse, Singapore, September 11-16, 2005.

4. $\quad$ Bruin, d., Kamp, F., Eddy, P. and Lagrand, K., WTW: UF/RO from technological novelty to full size application, Proceedings IWA Enviro 2002, Melbourne, Australia, 2002.

5. Burashid, K., Hashim, A., Kannari, T., Tada, K. and Iwahori, H., UF Membrane Performance Experience at Addur: Expectation, Reality and Prospects, Proceedings IDA World Congress on Desalination and Water Reuse, Singapore, September 11-16, 2005.

6. Caneja, J., Farinas, M. and Jimenez, A., Spanish cost data illustrate RO's competitiveness, Desalination \& Water Reuse, Vol. 15, No. 1, pp. 10-17, 2005.

7. Clunie, W., VandeVenter, L., Williams, S. and Garana, E., Comparison of pre-treatment alternatives for seawater reverse osmosis, Proceedings AWWA Membrane Technology Conference, Phoenix, USA, March 6-9, 2005.

8. Côté, P., Siverns, S. and Monti, S., Comparison of membrane-based solutions for water reclamation and desalination, Desalination, Vol. 182, pp. 245-251, 2005. 
9. $\quad$ Futselaar, H., Hoof, S. Van and Rosberg, R., Ultrafiltration Technology for Potable, Process and Wastewater Treatment, Proc. 9th World Filtration Congress, New Orleans, USA, April 18-22, 2004.

10. Galloway, M., Gottberg, A. V. and Mahony, J., UF for Seawater RO Pretreatment, Proceedings of AWWA Membrane Technology Conference, Atlanta, USA, March 2-5, 2003.

11. Gleuckstern, P. and Priel, M., Comparative Cost of UF vs. Conventional Pretreatment for SWRO Systems, Desalination \& Water Reuse, Vol. 12, No. 4, pp. 34-39, 2003.

12. Gottberg V. and Vaccaro G., Kuwait's giant membrane plant starts to take shape, The international desalination and water reuse, Vol. 13, No. 2, 2003.

13. Gottberg, A. V., Gagne, D., Vaccaro, G. and Elyanow, D., World's Largest Membrane-Based Reuse Project, Proceedings AWWA Membrane Technology Conference, Atlanta, USA, March 2-5, 2003.

14. Henthorne, L., Economic evaluation of membrane and conventional SWRO pretreatment - results from pilot study, Proceedings AWWA Membrane Technology Conference, Phoenix, USA, March 6-9, 2005.

15. Iwahori, UF membrane performance experience at Addur: expectation, reality and prospects, Proc. IDA World Congress on Desalination and Water Reuse, Singapore, September 11-16, 2005.

16. Menge, J., Haarhoff, J., Konig, E., Mertens, R. and Merwe, V., Occurrence and Removal of Giardia and Cryptosporidium at the Goreangab Reclamation Plant, Water Science and Technology, Water Supply, Vol. 1, No. 1, pp. 97-106, 2006.

17. MPW, Ministry of Public Works, 'Total cost of wastewater treatment', Statistical Book, 2001.

18. Tchobanoglous, G. and Angelakis A. N., Technologies for Wastewater Treatment Appropriate for Reuse: Potential for Applications in Greece, Water Science Technology, Vol. 33(10-11): 15-24, 1996.

19. Tortajada, C., Water management in Singapore, Water Resources Development, Vol. 22, No. 2, pp. 227 240, 2006. 